\title{
Ethnoastronomy as an academic field: a framework for a South American program $\dagger$
}

\author{
Alejandro Martín López \\ Instituto de Ciencias Antropológicas, Universidad de Buenos Aires \& \\ Consejo Nacional de Investigaciones Científias y Tecnicas, Argentina \\ email: astroamlopez@hotmail.com
}

\begin{abstract}
We present some methodological reflections based upon twelve years' experience working in South American ethnoastronomy. The aim is to propose a basis for a possible development plan for ethnoastronomy in this region. Taking as axiomatic that ethnoastronomy is a social science, we discuss issues such as the process of development of an academic discipline, the links between ethno- and archaeoastronomy, the idea of 'otherness', ethnographic methodology, the relevance of logics of practice, the relationship between orality and writing, and the dialectic relationship between change and continuity. In addition, we discuss possible ways to achieve the institutionalization of ethnoastronomy. We conclude by considering the importance of regional and international academic exchange.
\end{abstract}

Keywords. ethnoastronomy, South America, methodology, academic discipline, institutionalization

\section{Cultural astronomy as a social science}

The term 'cultural astronomy' (Ruggles \& Saunders 1993; Iwaniszewski 1994) has been used widely since the 1990s to encompass both archaeoastronomy and ethnoastronomy. This should have led to a fundamental recognition that what these fields of study deal with, using a variety of techniques, are the ways in which human societies construct their knowledge and practices concerning the sky and its phenomena (Iwaniszewski 1990, 1991). That is to say, they deal, above all, with social facts. Unfortunately, this evident truth is often disregarded by those who work in these fields.

Both human successes and failures in understanding the universe are clearly social products, in common with everything we do without exception, since we are social beings. This is especially true as regards the construction of systems of knowledge, since these are relevant for an important group of people within a society, and they require collective work among human groups. It follows that cultural astronomy must deal, as we have said, with social facts. Yet because, historically, cultural astronomy has developed mainly from astronomy, this fundamental issue is often disregarded. It remains crucial nonetheless.

One important consequence of studying social data is that methodology in cultural astronomy must fall within methodology in the social sciences. It follows that, in order to be meaningful, all work in this area must be cogniscent of the great debates within the social sciences. If we do not take into account current debates in anthropology, sociology, or the cognitive sciences, we cannot hope that cultural astronomy will make serious contributions. What is more, we run the huge risk of using common-sense conceptions instead of scientific categories. This is a very serious problem since many of the words used by social scientists also have a meaning in everyday language. Concepts such as space, territory, person, body, identity, and culture cannot be taken for granted. The

$\dagger$ Invited keynote lecture at Regional Meeting 
historical development of cultural astronomy has led many of those who practice it to use these key notions without problematizing them. $\dagger$ Likewise, it is of vital importance to understand the different theoretical schools in the social sciences, in order to situate any research in cultural astronomy adequately within the wider framework of ideas.

It has been long been discussed whether cultural astronomy should be regarded as an interdiscipline, a multidiscipline, a transdiscipline - there seems no limit to the possible prefixes. Although it has not produced any definitive conclusions, the debate has produced some key points of agreement. The first is that cultural astronomy brings together professionals who have very diverse academic backgrounds ranging from astronomy to anthropology, including physics, sociology, art history, engineering, mathematics, architecture, and so on. The undergraduate training of these professionals is strongly structured by the characteristic divisions between specialities within our universities. For this reason, in order to carry out this collaboration and to build a common language, it is an absolute necessity for any aspiring cultural astronomer, whatever their background, to thoroughly re-examine their methodological and epistemological assumptions by learning from other areas (Belmonte 2006: 46). And since the objects of study in cultural astronomy are social facts, social science is an essential area for those who have no background in it.

Ethnoastronomy, as part of cultural astronomy, is fully implicated in all of this. And it is from this starting point that we shall seek to outline some ideas for the development of a program for the development of ethnoastronomy in South America.

\section{Bourdieu's concept of an academic field}

The resistance to considering cultural astronomy as the study of social facts is also reflected in the long-term debate regarding 'externalist' and 'internalist' approaches in the study of science. The debate is basically between two opposing schools of thought: one that views science as a completely autonomous arena which is explained by its own internal rules, and therefore different from any other human production; and one that regards science as reducible to external factors, such as the political or economic context. Bourdieu (2003) proposed his 'field' concept to avoid this polarization in extremes. In our view it is a very important and useful concept in seeking to understand the situation in cultural astronomy and to devise a research program. In what follows we will summarize those of Bourdieu's concepts about scientific or academic fields that are most relevant in the light of this objective.

Bourdieu proposes that lying between the internal content of cultural productions and the context external to them is a relatively autonomous 'social world' that he calls the field (scientific, artistic, judiciary, etc.). Each field shares common characteristics with all the others, but also has its own specific social laws. Each specific field is included in the total social universe, but preserves a relative autonomy, reflected in specific rules that apply to the 'social game' that takes place within it. In fact, it is precisely this relative autonomy that characterizes a field. The different disciplines or areas within the scientific field are subfields whose relative autonomy is subject to broad variations. Owing to this relative autonomy, each field has a certain capacity to transform the demands of the global social universe inwards, a broad degree of autonomy implying a higher capacity to make this transformation.

$\dagger$ This academic term means to take a concept, a practice or a fact that appears 'natural' or 'obvious' to us and 'stand back' from it (i.e., try to forget our common-sense notions about it), so as to transform it into a scientific problem needing explanation. 
A field is defined by the set of objective relationships existing among the agents and institutions that form part of it, and the struggles and alliances necessary to preserve or transform these relationships. It is the structure of these objective relationships that sets what an agent or an institution can or cannot do inside the field, according to its position there. In fact, a fundamental alliance must exist between all the participants of a field - it is this that makes the field's existence possible. This requires that all of them share the illusio, that is to say they take on trust the importance of the social game that takes place in its interior.

An agent's position in a social field depends on the type, quantity and legitimacy of the capital it has. In the sense in which Bourdieu uses the term, there are many general forms of capital (economic, social, symbolic) and each field is characterized in turn by a specific type of capital (in the case of the academic field, this would be the scientific capital). Thus, the structure of the scientific field at any given moment is broadly determined by the distribution of scientific capital at the time. The scientific capital is a particular type of symbolic capital (one based on knowledge and acts of recognition) which consists of the recognition attributed by the agents of the academic field to a specific agent or institution.

Each field has a specific sense of play that is specific to it, which its participants acquire as they pass through it, and from which they discern the non-written rules of this social space. For each social agent, the socialization process along their particular path in the social field gradually constructs their specific habitus. In other words, by this process a number of acquired but nonetheless durable traits are embodied in the social agents. This is equivalent to incorporating, within the agent, visions and divisions - or modes of perception and classification of the world - that are objective characteristics of the structure of the field.

A field is constituted as such (i.e., comes into being) by means of a historical process that allows a growing autonomy with respect to the general social world. This implies having imposed relatively autonomous criteria governing what is or is not legitimate within it. Again, this process is historical and thus contingent-i.e., it could have not occurred under other circumstances. In fact, the divisions among many academic subfields, such as the separation between anthropology and sociology, or astronomy and physics, are clear examples of that. However, although it is historical and contingent it is not an arbitrary process. It is not possible to create divisions between academic fields at an individual's whim. The constitution of a field is a complex social and historical fact and does not depend on any one person's decision (Bourdieu 2003: 20-25).

From this point of view it seems that the constitution of ethnoastronomy as an academic field in South America will depend, to a great extent, on the capacity to achieve necessary alliances in the particular South American context. That requires agreement on what will constitute a minimal consensus over the game rules that will have sufficient legitimacy within the South American academic world. For this reason, it is necessary to understand the general characteristics of our regional academic field. Any attempt to make ethnoastronomy academically viable in South America must necessarily take account of its basic raison d'être.

\section{Is ethnoastronomy the long-lost sister of archaeoastronomy?}

Right from the start of the particular historical process that has shaped cultural astronomy, archaeoastronomy has been the star sister of the family. This can be seen clearly in the names of the 'Oxford' meetings themselves (they are 'International Symposia on Archaeoastronomy') and of the two most highly respected periodicals in the field 
(Archaeoastronomy: The Journal of Astronomy in Culture and the Archaeoastronomy supplement to the Journal for the History of Astronomy). The proportion of presentations on archaeoastronomy as opposed to ethnoastronomy at the Oxford Symposia is another good indicator. It is not only obvious that the practice of archaeoastronomy has led cultural astronomy studies throughout but also that it has often influenced the general methodological development of the field as a whole.

A good example of this influence can be seen in the preference within archaeoastronomy for studying hierarchical societies. Since these tend to produce more durable material remains and are therefore more accessible by means of archaeological techniques, the archaeoastronomy debate focuses on this type of culture. Not only has this resulted in the quantity of archaeoastronomical work dedicated to other types of societies being small; it has also generated a preference for the type of astronomy that appears in hierarchical societies. In the South American region, for example, many archaeologists simply assume that hunters-gatherers did not have any meaningful astronomical knowledge.

\section{Ethnoastronomy and 'otherness'}

Ethnoastronomy is linked to ethnology. It uses the tools and methodologies of ethnology in the study of astronomical conceptions. What are the consequences of this?

It can be said that the long historical process of its development has formed ethnology into the study of 'otherness'. Historically, 'ethnicity' was a term that referred to societies different from the academic 'Western' culture. It is more useful, however, to understand ethnicity as a dimension of identity which, in common with other aspects of identity, is deeply linked to the establishment of opposition and boundary relationships with an 'other' rather than a specific set of features that would characterize a 'we' (Barth 1976). The latter will change as necessary in order to maintain those contrasts that are relevant at any given moment.

It follows that the term 'ethno-' should not be applied solely in reference to aboriginal groups or other 'minorities' in relation to their dependence on the global capitalist system. Instead, it should signify a particular approach to the study of all social groups, an approach that can deal with any society. One of the methodological cornerstones of such an approach is the deconstruction of what the researcher regards as common sense: in other words, the recognition of the researcher's own habitus. Of course, it is not possible to strip off-as if it were clothing - the habitus in which we are socialized, either in the general social field or in the more specific academic field. Indeed, in order to be a meaningful scientific study, ethnological work must be classed as legitimate for the academic field. But in order to come closer to other conceptual universes and make it possible to reflect upon them from the perspective of the academic world, it is essential to be able to reflect upon the 'place' from which we are looking and learn to 'see' the 'places' from which the 'other' builds his discourse.

Anthropological strangeness, the process of transforming familiar, common-sense things into stange, or unfamiliar, ones - in other words of finding the limits of one's own social universe - is far from simple. When we study societies whose practices are very distant, we can certainly find it extremely difficult to leave behind our own assumptions. This can make it impossible to perceive some of 'their' fundamental practices or concepts. For example, if we tried to use a restrictive definition of astronomy to deal with a culture for whom phenomena that 'Western' academics would call atmospheric are inseparable from those they would call astronomical, we would fail to grasp a fundamental aspect of the conception that the culture in question had of the cosmos.

On the other hand, when we study a culture that is very close to us - such as the academic astronomer's own - we run the risk of taking some key concepts for granted. 
That is, we may take the practices and representations that belong to a specific cultural context as human universals, and this is an error independently of how correct these practices seem to us. An example of this is the importance of accuracy in astronomical measurements. In Western scientific astronomy, the accuracy of measurements is of key importance. This leads many researchers to view precision as a central concept in all astronomies. However, when it comes to the astronomical conceptions of many other cultures, the 'fuzziness' of measurements is in fact both necessary and desirable.

Both these kinds of study are necessary. Yet there is a notorious lack of ethnographic studies of astronomical practices in 'Western' societies. Here I refer both to academic culture and to other western astronomical cultures that might be referred to as 'popular astronomical traditions' in the sense they are not transmitted by official learning institutions. The study of these 'popular astronomical traditions' is what Stanisław Iwaniszewski has called 'socioastronomy', although my proposal for the concept 'ethno' implies that it can be dealt with perfectly well from an ethnoastronomical perspective. The wide and diverse set of 'popular astronomical traditions' or 'popular astronomies' presents a veritable panorama, although many of them are forgotten. A very interesting case is that of Creole and European immigrant traditions within rural South America, which are very important in contextualizing studies on aboriginal astronomies in this region.

Cultural astronomy in general and ethnoastronomy in particular tend to be seen in the context of the popularization of 'cultural studies' and the multiculturalism policy of the 1980s. This conceptual frame has certainly made our studies legitimate and given them a visibility they did not have before. But this approach has certain risks, in particular those that derive from a 'domesticated' vision of culture. From this point of view, the 'cultural' realm is divorced from social, economic and political processes. 'Culture' is identified with the cultural production field as it exists in the western world: its autonomy is exaggerated, and conceptions of what is 'cultural' serve to provide a comfortable margin whereby we can speak about differences and 'respect them' while the social, economic and political processes drive towards homogenization. The work of ethnographers, particularly in South America, must not encourage an ideological use of the concept of 'culture' that supports the subjugation of minority groups. Culture cannot be separated from social life in general, since no cultural production field is completely autonomous from the general social universe. In this way our studies should not only stimulate respect for the differences but take notice of, rather than conceal, situations at oppression in the cultures we study. Because of the respect that astronomical knowledge engenders both in the academic world and among the public, studies in ethnoastronomy have a huge potential for raising awareness of and promoting minority groups. Connections with educational institutions are particularly important in this regard.

\section{Field and theory}

Fieldwork is a key aspect of ethnology and, therefore, of ethnoastronomy. Despite the fact that quite a few researchers who have no background in the social sciences seem to assume that no special training is required in order to undertake fieldwork, it actually involves a complex set of techniques that must be learned. There are numerous good existing handbooks that can be used (e.g. Hammersley and Atkinson 1994); alternatively, courses run by qualified ethnographers who are also well trained in anthropological theory are an excellent possibility and have the advantage of face-to-face interaction. In many South American countries there are degree- and postgraduate courses available. But since training for fieldwork and for dealing with 'strangeness' is, above all, a training of one's own mind and especially of one's own body, nothing else can match field experience working alongside qualified ethnographers. 
Numerous well-tried techniques can be applied in the field (unstructured, semi-structured and structured interviews, opinion polls; records in the form of notes, audio or video; the preparation and use of drawings and diagrams; etc.) but the most important is undoubtedly the participant's observation (in all its variations). In this kind of observation, the observer gets involved, to varying degrees, in the everyday life of the culture $\mathrm{s} /$ he is studying, and this permits us to study that culture as a whole and as a living thing. Only in this way it is possible to understand the role of a specific piece of the cultural experience, because to do this is fundamentally a holistic and integral approach to the society in question. It will often be the case that observations and conversations referring to apparently disconnected issues such as the state of the cattle or the price of potatoes will unexpectedly provide valuable insights into the system of classification of celestial beings. It is not possible to predict such relationships, although experience gained in such interactions will gradually help the investigator to suggest other possible connections.

Despite this, work in ethnoastronomy to date shows a clear preference for interviews, and generally for quite structured ones. This carries serious risks. Of course, this choice in itself reflects the false application of paradigms belonging to physics and astronomy. Such techniques give a comfortable sense of familiarity and objectivity to astronomers, many of whom tend to use these methods exclusively. This is not to deny that opinion polls and interviews can be very useful when used together with participant observation and other techniques, but when used in isolation they can seriously bias the results of the research.

A very interesting technique in the specific case of ethnoastronomy, which must be of course used in conjunction with the others just mentioned, is the use of planetaria. When the researcher has a solid, confident relationship with an informant, working together in a planetarium has many advantages. In a short time it is possible to reconstruct the configuration of the sky at many different times of the year and to simulate phenomena that are rarely visible for one reason or another, such as the climate. However it is important, when using those instruments, to be aware of the impact that the planetaria and the simulations that can be performed inside them can have on the informants, for whom they can become very special places.

The researcher in the field frequently asks himself to what extent his presence influences the phenomena he wishes to observe. It is impossible to 'step outside' of the situation; there is no neutral social place. We are always somebody for those whose culture we study. First and foremost, then, we must strive to comprehend the roles that they assign to us - to know where it is they address us from or whence they show themselves. This, combined with the exchange of perspectives with other researchers who work in the same culture and who have been assigned other roles, allows us to improve our understanding. This is a key issue regarding gender discrimination and for this reason it is important that a greater proportion of women participate in the research.

In the same manner, according to deeply rooted prejudices - including particularly the desire to search for an 'ancient tradition' that can be rescued — we privilege old people and leaders as informants. In doing this we lose track of young people, children, adolescents and other groups' perspectives and dynamics. Ethnographic sampling techniques (which are not similar to statistical sampling) seek to avoid this kind of discrimination by varying the distribution of informants in terms of gender, age, place of residence, social role, etc.

Another important point to consider is the relationship between field and theory. In ethnoastronomy, as in science in general, theories must be used as 'maps' or mental models that are useful in perceiving the world. But a map is not the reality; it is a simplification of the reality, designed with particular aims in mind, always open to improvement. 
In the same way, when we want to plan a car journey we use the road map and if we want to climb a mountain we use a topographic map. Different research objectives involve different conceptual patterns. Just as, in order to be useful, a map must be simpler than what it represents, so theoretical models are simpler than the reality they represent.

Although every researcher necessarily starts from some viewpoint, theoretical models should not be transported en bloc into the field, as conceptual 'boxes' into which reality is forced to fit. The researcher must keep an open mind that allows his observations to suggest the most adequate conceptual patterns. This is especially true when working on a particular ethnographic case for the first time. There certainly exist specific instances where a researcher goes to do fieldwork to prove a particular hypothesis, but these are special cases, and in fact they require previous analysis of the specific ethnographic case in order to determine if the conditions will actually permit the hypothesis to be tested.

An 'epistemological surveillance' must be performed upon the implicit mental images that can influence our analysis and observations. Due to the fact that our academic culture is strongly based on verbal communication, we tend not to pay attention to diagrams, sketches and illustrations. In fact, crucially important aspects of the perceived organization of the world are often encapsulated within images and other arrangements of data. Many forms of information organization, such as lists and tables, are typical of specific technologies, such as writing (Ong 1996). An example is the use of fixed cosmological patterns in different 'layers' that succeed one another in an established and immutable order. Something similar occurs with our own metaphors: images and metaphors are like implicit mental patterns that the researcher applies without noticing.

Given that, as we have discussed, the aims of research in ethnoastronomy are social in nature, its principal conceptual framework will be that of the social sciences. Beyond the classic authors in the field, it has been our personal experience that some authors seem to be particularly useful. These include Pierre Bourdieu, and especially his contributions analyzing the links between social and practical structures through the notions of field and habitus and the fundamental concepts of logics of practice (Bourdieu 1972; 1997; 2007 ; 2010). Marshall Sahlins' concepts of mythopraxis and symbolic refunctionalization (Sahlins 1988; 2006) present a way of understanding how myth functions as a form of historical conscience that is both interesting and useful for our purposes. Similarly, we can benefit from the contributions of Peter Gow (2001), Fredrik Barth - who is highly relevant for his Studies about ethnicity (Barth 1976) and the construction of cosmologies (Barth 1987) — and authors like Walter Ong (1996) and Jack Goody (1996) who are very important for understanding the relationships and differences between oral and written cultures.

As regards more specific theoretical frameworks, it is this author's view that collaborative work coordinated at a regional level can provide a solid basis for the construction of middle-range theories.

\section{The logic of practice}

Another way in which participant observation is fundamental, within the framework of a total or holistic ethnography, is that it avoids our works being centered upon verbal communications and disregarding the vital role of the body. This is especially important if we are interested in understanding those pieces of knowledge that are not explicitly formulated, but which form the basis for explicit knowledge. These logics of practice, which the members of a society acquire by means of primary socialization, form the foundations upon which cosmos-conscious conceptions are built. In order to have access to them, it is essential to study the bodily aspects of daily life. Here we are not just 
referring to special uses of the body as, for example, in dances and rituals but also the use of the body as a symbolic operator in everyday life. Bourdieu's concept of habitus is very useful for thinking about the processes by which this type of knowledge is incorporated.

The term 'cosmovision', or worldview, should be reserved for non-explicit pieces of knowledge - common notions about the nature of the world, strongly associated with specific social values (for which the specific term 'ethos' is sometimes used). The term 'cosmology' should only be used for explicit and systematic constructions, frequently associated with the labor of specialists. If these terms are not distinguished from each other, they lose conceptual efficacy.

An example is useful here. Among the Toba and Mocoví from Chaco, things experienced in dreams are as much part of the real world as those experienced while awake. This to them is simply common sense, assumed by everybody when they analyze the different events of daily life. In the same way, it is self-evident for these groups that different entities and substances can enter and leave people's bodies. These ideas and the everyday practices associated with them form part of the cosmovision or worldview of these peoples. Different specialists (shamans, teachers, elders, evangelical pastors, etc.), implicitly taking these things for granted, construct different systems of ideas about the nature of the sky, partially based upon their experience of travelling through this region during their oneiric experiences.

\section{Orality and writing}

Most work in ethnoastronomy produced in South America deals with cultures where orality is fundamental. That situation requires a particular approach, one that deconstructs our own ideas regarding the relationship between the oral and written word (Ong 1996). This is because - although we tend to forget it - writing is not innate to human beings; it is a technology, and possibly the most revolutionary one.

In oral contexts, the word is not an object 'out there' but an event that occurs in time. The discourse itself is not a 'visual design' that can be seen on a page but something that is perceived using the memory to retain in the mind the temporal sequence of the words. Oral communication in 'primarily oral' cultures occurs in face-to-face interactions. It is true performance, which involves the body and the senses. In fact, body rhythms, especially respiratory ones, play an essential role in memorizing.

The notions of 'text' and 'author' lack a precise meaning in oral contexts. What is expressed orally is not an enunciation of a fixed text; this is a different type of communication, one in which the interests of, and relations between, the speaker and his audience determine an important part of the content. There is no 'fixed canon' to compare: the art of the narrator is not in saying something never said before, or in repeating a text literally, but in producing a particular resonance in his audience. He certainly appeals to the authority of tradition, but in a flexible and indistinct way, one that lets him incorporate new things as if they already formed part of the ancient traditions.

For these reasons, in the absence of writing, wider and integrated thinking takes place mainly during communication-during conversation with others. This is where the systematic production of a cohesive body of knowledge takes place. It follows that the social characteristics of cognitive systems are very strong.

This said, most of the societies we study are not primarily oral societies, but ones with long and complex processes of marginal contact with writing. These circumstances have their own dynamics (Goody 1996). In these situations, the physical written document often becomes an object of power in itself, independently from the meaning of the text. 
This has occurred repeatedly in South America with the Bible, but also with identity documents and a variety of other artifacts containing writing.

One of impacts of writing that is usually ignored, but which has a particular importance for ethnoastronomy, is that it brings with it predetermined ways of organizing and classifying information. Astronomical knowledge is frequently expressed in the form of tables and lists, ways of organizing data items that seem to be linked with writing.

When we are attempting to interpret aspects of cultures with marginal access to writing, the illustrations that accompany our texts are often more important than the text itself. This must be also taken into account when interpreting the texts produced by the members of these cultures.

Many of the societies to which we refer are in contact with modern communications technologies from cellphones to videos. In some cases, they have come into contact with these technologies but have had little or no previous contact with more traditional written documents. This presents new challenges for ethnoastronomical work and should not be ignored.

\section{Change and continuity}

Two issues that are fundamental for South American ethnoastronomical studies are the preconceptions that are common within academic culture, which is not oral, and the particular forms of historical conscience that have come to exist in the Western world. These together have led us to favor a perception of pre-Columbian cultures as cultures without history, static, isolated, and homogeneous. Some have suggested that structuralism has reinforced that impression, and this has led to a number of ethnographies centered on the concepts of rescue and acculturation. But it is important to understand that American societies were already dynamic even before the arrival of the Spanish. Pre-Columbian America had an ethnic dynamic that was very fluid, so even though the conquest introduced some dramatic changes, change and exchange were not in themselves unknown to Americans.

On the other hand, as several recent studies have shown (e.g. Sahlins 1988; Gow 2001), myth is itself a form of historical conscience, one that confronts time and change using its own tools.

Interethnic contact has not only always existed but has been an essential factor in the construction of ethnic identities (Barth 1976). In fact, ethnoastronomical studies frequently fail to recognize the complex issues of ethnic identity. Ethnic identity should not be thought of as a given item of data, but as one that it is important to problematize in many different ways. Yet the tendency has been to treat the groups under study using models suited to nation states ('one language, one territory, one culture') in an attempt to establish 'the' astronomy of a certain culture. The situation has been worsened by the uncritical use of an ethnic terminology that owes far too much to the 'territorial arrangement' imposed by the European conquerors. It is clearly important to understand that hunter-gatherer societies are not internally homogeneous. Struggles for leadership involve important cosmological elaborations which can result in true sub-traditions (Barth 1987).

\section{The ethnohistorical perspective}

For a thorough understanding of ruptures and continuities, those who carry out ethnoastronomical studies should examine ethnohistorical perspectives, since they add depth to our understanding of social processes. In South America some very important developments have recently taken place in ethnohistorical studies, using key colonial sources (Boccara 2003; Platt et al. 2006; Nacuzzi 2006; Lorandi 2008; Ramos 2010). Some 
ethnoastronomical studies have begun to utilize these perspectives, but they are still small in number. In particular, there is much to explore in the ethnohistorical sources from the 19th and 20th centuries, including letters and local records.

Ethnohistorical perspectives, examined from a regional viewpoint, permit the establishment of useful comparisons. This is because we are not comparing isolated features. We must give meaning to a single feature by reconstructing the field of possibilities in which this characteristic is involved, in the same way that any sound in a linguistic system takes its meaning from its relationships with the other possible sounds that we can choose. Ethnohistorical research, regionally coordinated, allows us to deal with structures and processes that constitute these fields of possibilities.

\section{0. 'Grouped' studies}

Where there is a shortage of material or human resources to aid our investigations, instigating studies that are 'grouped' according to some relevant criterion offers interesting advantages. One of the most fruitful ways of grouping investigations is by region. Another is to focus on the same linguistic family. Concentrating the efforts of one or more researchers from different groups in this way can provide a very good basis for fruitful comparisons and feedback. At the same time, it increases the possibility of moving beyond the initial, merely descriptive, phase to deeper levels of analysis. It also helps to minimize the effort that would be wasted in undertaking a multiplicity of isolated case studies: uncovering variety in this way might seem an attractive proposition but is ultimately useless.

It is important that grouped studies should avoid either extremely specific or extremely general cases. An overspecific focus will fail to identify and address theoretical issues that are common to comparable case studies. An overgeneral approach risks making superficial comparisons of isolated features without considering the context in which those characteristics take place. When conceptions are compared in this way, they all seem more or less similar.

\section{Institutionalization}

Institutional incorporation is of vital importance for ethnoastronomy in South America. But given the way in which, for historical reasons, the academic fields are configured in different regions, no uniform vision or single development strategy applies across all of South America. We can, however, make some general suggestions concerning institutional niches that could provide possible ways forward.

It is possible to develop research projects related to ethnoastronomy from various perspectives, including symbolic anthropology, social anthropology, the anthropology of religions, the anthropology of landscape or the anthropology of the body. It is possible that such projects could be inserted into existing projects that include an element of ethnoastronomy. This method seems to be quite viable. At a postgraduate level, it is even possible that someone trained in astronomy could be accepted into an anthropology program (the opposite is practically impossible).

There is good potential for developing ethnoastronomy projects in the context of ethnohistory, another interesting field with a growing presence in many South American countries. The history of science could be a good possibility in some countries, especially for certain topics linked to the study of 'popular astronomies' or academic astronomy. Related to this are studies dealing with educational issues arising from obstacles linked 
to cultural diversity. An interesting possibility is that teacher-training institutes could become involved in the financing of initiatives of this kind.

In the case of academic astronomy the prospects are less auspicious, at least for the time being. Most astronomers seem unwilling to regard ethnoastronomy as an activity within their own field, and it is very difficult to obtain funding to lead an investigation that has this focus. An option that is often followed is to undertake 'official' research in more conventional topics while running an ethnoastronomy project in parallel. This solution is clearly not ideal but in some cases provides the only opportunity. IAU sponsorship of initiatives for the International Year of Astronomy 2009 provided some scope for ethnoastronomy work that could be considered to be 'extension' or 'diffusion'.

Lest we continue to rely solely upon the personal initiative of individual scholars, it is necessary to develop strategies for the discipline as a whole. Doctoral theses have a key importance in this regard because they give legitimacy to the core of the academic field. We must work together to bring about conditions that stimulate the production of good-quality theses in ethnoastronomy. Postgraduate courses are clearly a vital prerequisite. An optimal strategy in the short term might be to encourage the inclusion of ethnoastronomical aspects within theses focused mainly upon other themes.

Extension courses and diffusion activities, among both the academic community and the public at large, are extremely important in increasing awareness of ethnoastronomy. Planetaria are hugely important in this context, as are amateur associations. A special effort must be made to provide these fora with high-quality projects and presentations suitable for the public to whom they are oriented. Ethnoastronomy has a huge potential to stimulate the public, since it not only combines the social universe with observations of the sky but also reveals how people conceive themselves to be in direct relationship with the celestial realm. It is especially important to develop cultural astronomy programs for planetaria, since the public sees them as rightful places of astronomical knowledge. In consequence, these places have for the general public the power of legitimizing the astronomical knowledge displayed in them.

\section{Communication and exchange}

From all that we have said, one obvious conclusion is that effective communication is a necessity if ethnoastronomy is going to become a recognized academic field in South America. A number of projects undertaken in isolation have reproduced concepts already dealt with by others, for the simple reason of lack of communication. Therefore the circulation of theses and articles is vital. There are various obstacles to achieving this goal, of which the biggest is the problem of authors' rights: articles in refereed journals are not always freely available. Another problem - a consequence of the variety of institutional strategies for fitting ethnoastronomy into the broader infrastructure - is that the relevant articles are scattered across diverse publications pertaining to many different disciplines and regional scales.

In this context, it will be crucial to strengthen the role of the Sociedad Interamericana de Astronomía en la Cultura (SIAC). This organization is a means by which South American cultural astronomy can obtain greater visibility among the global community in the field. At the same time, it could generate much greater interaction among colleagues throughout America by, for example, the intensive use of new internet communications tools (blogs, facebook, web sites, video conferences, etc.).

One of the first steps could be to generate a databank of doctoral and masters theses relevant to cultural astronomy issues. The Society could also make available a list of the journals in which relevant articles are being published and perhaps also, where possible 
(given copyright restrictions, etc), make available copies of the articles themselves or, at the least, short summaries of articles supplied by researchers themselves for circulation among their colleagues.

Last but not least, it is extremely important to encourage healthy debate in order to improve quality standards. We should also stimulate and orientate youngsters who are just starting out: this is an excellent way to create opportunities in neighboring countries. Our determination to build up SIAC as a forum for debate and exchange will be a good indication of the maturity of the ethnoastronomical community in South America.

\section{References}

Barth, F. 1976, Los Grupos Étnicos y sus Fronteras, Fondo de Cultura Económica, México D.F. Barth, F. 1987, Cosmologies in the Making: a Generative Approach to Cultural Variation in Inner New Guinea, Cambridge University Press, Cambridge.

Belmonte, J. A. 2006, La investigación arqueoastronómica. Apuntes culturales, metodológicos y epistemológicos. In J. Lull (ed.), Trabajos de Arqueoastronomía. Ejemplos de África, América, Europa y Oceanía, Agrupación Astronómica de La Safor, Valencia, pp. 41-79.

Boccara, G. 2003, Rethinking the margins/ thinking from the margins: culture, power, and place on the frontiers of the New World. Identities: Global Studies in Culture and Power 10(1), 59-81.

Bourdieu, P. 1972, Esquisse d'une Theorie de la Practique, Droz, Paris.

Bourdieu, P. 1997, Razones Prácticas. Sobre la Teoría de la Acción, Editorial Anagrama, Barcelona.

Bourdieu, P. 2003, Os Usos Sociais da Ciência. Por uma Sociologia Clínica do Campo Científico, Universidade Estadual Paulista, São Paulo.

Bourdieu, P. 2007, El Sentido Práctico, Siglo XXI Editores, Buenos Aires.

Bourdieu, P. 2010, El Sentido Social del Gusto. Elementos para una Sociología de la Cultura, Siglo XXI Editores, Buenos Aires.

Goody, J. (ed.) 1996, Cultura Escrita en Sociedades Tradicionales, Editorial Gedisa S.A., Barcelona.

Gow, P. 2001, An Amazonian Myth and its History, Oxford University Press, New York.

Hammersley, M. \& Atkinson, P. 1994, Etnografía. Métodos de Investigación, Paidós, Barcelona.

Iwaniszewski, S. 1990, Astronomiia kak kul'turnaia sistema. In A. A. Gurshtein (ed.), $\mathrm{Na}$ Rubezhakh Poznaniia Vselennoy, Nauka, Moscow, pp. 67-73.

Iwaniszewski, S. 1991, Astronomy as a cultural system. Interdisciplinarni Izsledvaniya, 18, 282288.

Iwaniszewski, S. 1994, De la astroarqueología a la astronomía cultural. Trabajos de Prehistoria, $51(2), 5-20$.

Lorandi, A. M. 2008, Poder Central, Poder Local. Funcionarios Borbónicos en el Tucumán Colonial. Un Estudio de Antropología Histórica, Editorial Prometeo, Buenos Aires.

Nacuzzi, L. R. 2006, Tratados de paz, grupos étnicos y territorios en disputa a fines del siglo XVIII. Investigaciones Sociales 17, 435-456.

Ong, W. J. 1996, Oralidad y Escritura. Tecnologías de la Palabra, Fondo de Cultura Económica, Buenos Aires.

Platt, T., Bouysse-Cassagne, T., \& Harris, O. 2006, Qaraqara-Charka: Mallku, Inka y Rey en la Provincia de Charcas, Siglos XV-XVII: Historia Antropológica de una Confederación Aymara, IFEA-Plural Editores-CIAS, La Paz.

Ramos, G. 2010, Muerte y Conversión en los Andes. Lima y Cuzco, 1532-1670, IEP, IFEA, \& Cooperación Regional para los Países Andinos, Lima.

Ruggles, C. L. N. \& Saunders, N. J. 1993, The study of cultural astronomy. In C. L. N. Ruggles \& N. J. Saunders (eds), Astronomies and Cultures, University Press of Colorado, Niwot, pp. 131.

Sahlins, M. 1988, Islas de Historia. La Muerte del Capitán Cook. Metáfora, Antropología e Historia, Gedisa Editorial, Barcelona.

Sahlins, M. 2006, Cultura y Razón Práctica, Gedisa Editorial, Barcelona. 